\title{
A Critical Discourse Analysis of the Use of Metaphor in Online Car Advertisements
}

Rita Hartati ${ }^{1}$, Ebrahim Panah $^{2}$ \& Hafizan Matsom ${ }^{3}$

${ }^{1}$ State University of Medan, Indonesia \& ${ }^{2,3}$ University College of Yayasan Pahang, Malaysia

\begin{tabular}{|c|c|}
\hline ARTICLE INFO & ABSTRACT \\
\hline $\begin{array}{l}\text { Article history: } \\
\text { Received May 30, } 2021 \\
\text { Revised June 30, } 2021 \\
\text { Accepted July 02, } 2021\end{array}$ & $\begin{array}{l}\text { The objectives of the current study are threefold: a) to investigate } \\
\text { what types of metaphors are used in Arab and Western car } \\
\text { advertisements and why they use them, b) to explore how metaphors } \\
\text { are used in Arab and Western car advertisements, and c) to explore } \\
\text { how cultural attributes are used along with metaphors in Arab and }\end{array}$ \\
\hline $\begin{array}{l}\text { Keywords: } \\
\text { Advertisement } \\
\text { Metaphor } \\
\text { Cultural attributes } \\
\text { Critical discourse analysis } \\
\text { Arab } \\
\text { Western. }\end{array}$ & $\begin{array}{l}\text { Western car advertisements. The study adopted a descriptive } \\
\text { approach through content analysis using three models: cultural } \\
\text { (Hofstede, 2005), metaphorical (Lankoff \& Johnson, 1980), and } \\
\text { contrastive discourse analysis (Farclough's, 2001), approaches to } \\
\text { analyze the data. The study sample comprised } 30 \text { car advertisements } \\
\text { from Holland, France, Germany, Italy, the US, and Arab countries, } \\
\text { each with five advertisements published online in 2016. The findings } \\
\text { of the study show that car advertisements frequently use metaphorical }\end{array}$ \\
\hline $\begin{array}{l}\text { Conflict of Interest: } \\
\text { None }\end{array}$ & $\begin{array}{l}\text { strategies. In addition, the study revealed differences between Arab } \\
\text { and Western advertisements in terms of the employment of cultural }\end{array}$ \\
\hline $\begin{array}{l}\text { Funding: } \\
\text { None }\end{array}$ & $\begin{array}{l}\text { attributes. Finally, the study also indicated that even within the } \\
\text { Western context, there is a different use of metaphorical strategies } \\
\text { with subtle differences. }\end{array}$ \\
\hline \multicolumn{2}{|c|}{$\begin{array}{l}\text { Corresponding Author: Rita Hartati, English Literature, Faculty Languages and Arts, State University of Medan. } \\
\text { E-mail: ritahartati@unimed.ac.id }\end{array}$} \\
\hline \multicolumn{2}{|c|}{\begin{tabular}{|ll} 
(C) $\left(\begin{array}{l}\text { (C) Rita Hartati, Ebrahim Panah, Hafizan Matsom } \\
\text { This is an open access article under the CC BY-SA 4.0 international license. }\end{array}\right.$ \\
\end{tabular}} \\
\hline
\end{tabular}

\section{Introduction}

Language in both spoken and written forms plays a crucial role in communication and socialization. The language process structures the thinking ability and the clarification of meaning. In addition, language has a close tie with culture. Culture comprised a class of people with joint and shared understanding who communicate and interact through language and symbols. Advertisements, in the cultural context of the target language community, have the roles of communication and social process to affect its audience.

Advertisement aims to communicate, influence and manipulate, and persuade people into buying products or services (Morris \& Waldman, 2011). One of the persuasive strategies of advertisements is a metaphor, which has a close relationship with the culture of the language (de Mooij \& Hofstede, 2011). A metaphor is a figure of speech that contains an implied comparison, where a word or phrase primarily employed for one thing is applied to another. Metaphors create concepts beyond experience and require us to stretch our imaginations to build meanings (Morris \& Waldman, 2010: 943). Metaphor comprises tenor (the main subject) and vehicle (transfer qualities of one idea to another) (Kaplan, 1990). For example, in the sentence 'dreams are chocolate', the dream is tenor, and chocolate is the vehicle. Kovecses (2010) associates metaphor with the formula 'A is $\mathrm{B}$ ', in which the domain 'A' can be understood through the source domain 'B'. Source domain is referred to the conceptual domain, and the audience draws metaphorical expression from this conceptual domain to make sense of another conceptual domain. For example, the curtain of the night is an example of a metaphor. It is argued that metaphors are split into three main categories: structural, ontological, and orientational (Kovecses, 2010). Structural metaphors introduce similarities between concepts and objects: "Ideas are food", as both can be eaten and digested, and "argument is war" as both can be fought. Ontological metaphors refer to concepts in terms of objects, substances, or discrete entities, as in "He broke down. Orientation metaphors use one notion structured in terms of another in spatial orientation: "up is happy, down is sad", and are based on culture, not on random choice. 
Metaphors are used in both textual and visual forms. Texts in advertisements play an essential role in attracting and influencing the audience. The language of advertisements offers vast information and describes different aspects of the product, such as its characteristics, uses, functions, or styles (Puspasari et al., 2012). On the other hand, modern advertising relies heavily on visual metaphors, as images sell everything, and visual metaphors- also known as pictorial metaphor, analogical juxtaposition are highly structured images created to capture the viewer's attention and push them to build one or more metaphorical correspondences between concepts that are depicted or cued by the image itself to highlight specific features of the product to be sold (Kadry, 2016).

One of the approaches to the analysis of advertisement is critical discourse analysis (CDA). CDA refers to linguistic and psychological approaches to the analysis of data from a distinctly critical stance (Paltridge \& Burton, 2000). In such analysis, the textual analysis (i.e., description), the discourse (i.e., interpretation), and social practice (explanation) are taken into account (Fairclough, 1993, 2001).

The current study finds that although there is a strong relationship between cultural attributes and metaphor usage, and CDA, advertisements are not taking into account these elements, and their work may consequently lead to failure (de Mooj, 2010).

\subsection{Problem statement}

Studies show that cultural values vastly affect metaphors in advertisements (Hofstede, 2005; Lankoff \& Johnson, 1980). Business owners and advertisers invest vast amounts of money in advertising their products and services. However, there are many reports of advertising failure (Puspasari et al., 2012). The main reason is that the advertisers do not consider the cultural values of the target audience (de Mooj, 2010; Hofstede, 2005). It is argued that even among familiar nations, there are differences in terms of metaphorical strategies in advertisements (Morris \& Waldman, 2011).

Arab counties are continuously and growingly using metaphors and cultural values in advertisements to capture the audience's attention and deliver their persuasive messages. Car advertisement is among the top ten culture-bound advertisements, and car companies invest an immense amount of money in advertising their products (Morris \& Waldman, 2011). For example, Toyota annually invests a tremendous amount of money in advertisement to preserve its first place among the car factories (adbrand.com) even though Toyota is already a globally recognized and famous brand. To make profits out of their advertisements, the advertisers should consider the cultural values of the target audience when designing their advertisements. Although car giants heavily rely on the use of metaphors and cultural attributes in their marketing, few studies are reported on the impact of cultural values on the advertisements (see de Mooj, 2010; Morris \& Waldman, 2011; Puspasari et al., 2012).

Different cultures show different preferences in the car advertisement category (Morris \& Waldman, 2011); however, in the Arab context, it is unclear and unexplored. It is not clear how metaphor is used in Arab car advertisements to manipulate and persuade customers. There is very little knowledge about the use of cultural features and metaphors in Arab advertisements. Very few, if any, comparative studies were conducted between the use of metaphor and cultural attributes in the view of CDA in Arab and western countries in literature.

Car advertisement in the western context indicates that people with different cultures have different preferences regarding car advertisement and selection (DeMooij, 2011). Morris and Waldman (2011) studied the use of metaphorical strategies in the car, food, beverage, and insurance advertisements using Hofstede's (2005) model and Lakoff and Johnson's (1980) model. They indicated that different western countries use quite different metaphors and cultural attributes in their advertisements to capture the audience's attention and manipulate them to purchase the products. Puspasari et al. (2012) studied the use of metaphor in car advertisements and reported that advertisers target a wide range of audiences through personification and ontological metaphor; however, the study did not compare the cultural aspects in advertisements limited to textual analysis. Morris and Waldman (2011) call for a comparative study in the other continent and crossculturally. Agnes (2009) suggested that further study on CDA of metaphor in media is needed to be undertaken.

In the Arab context, Al Jumah (2007) compared metaphor in English and Arabic in general business, not advertisements. The study only analyzed the text and did not deal with visual metaphors. El-daly (2011) discussed advertising discourse in the Arab context, but he did not focus on metaphors and cultural attributes. Gully (1996) presented a discussion on the relationship between language and culture in advertising discourse, but he did not study the use of different metaphors and cultural attributes. In a novel study, Kadry (2016) elaborated on visual metaphor and its issues in advertisements. However, she did not focus on the use of metaphor in car advertisements in the Arab context. Therefore, the current study is undertaken to bridge the gap in the literature.

SALTeL Vol. 4, No. 2, 2021: $25-36$ 


\subsection{Research Objectives}

Objectives of this article are:

1. To investigate what types of metaphors are used in Arab and Western car advertisements \& why.

2. To explore how metaphors are used in Arab and Western car advertisements.

3. To explore how cultural attributes are used along with metaphors in Arab and Western car advertisements.

\subsection{Research Question}

1. What types of metaphors are used in Arab and Western car advertisements, and why?

2. How are metaphors used in Arab and Western car advertisements?

3. How are cultural attributes used along with metaphors in Arab and Western car advertisements?

\section{Literature Review}

This section presents studies on metaphors and cultural attributes in advertisements in a global context and the Arab world, respectively. In addition, the studies are presented according to the year of publications in each context.

Agnes (2009) investigated how media uses metaphor to manipulate people. The researcher seeks the relationships between individual psychology, media, and metaphor through a case study of the metaphor used in the cosmopolitan magazine, advertisements of a popular women's fashion magazine. The author states that people thinking is structured through metaphor. The author decides that media can affect the way people and societies build abstract concepts such as health, interpersonal relationships, and beauty. The author concludes that advertising employed several tools and tricks to impact people and pursued them to purchase products. However, this study did not analyze the use of metaphor in cars.

Martín de la Rosa (2009) analyzed several visual metaphors, including car advertisements using Fairclough (1993) and Hodge and Kress (1993). Her study shed light on some persuasive strategies used by advertisements and found that advertisements enhance some values such as style, freedom, volume, modernity, and appearance to manipulate the people to buy the products. The finding of this study is impressive; however, the number of car pictures was limited, and there was no comparison across cultures.

Zhang and Gao (2009) focused on the use of conceptual metaphors in western advertisements. The study aimed at deepening the insights into the persuasive metaphorical strategies used in western advertisements to encourage the audience to buy their products. The study has several findings: first, the cognitive principle and communicative principle raised by relevance theory constrain the activated mappings within metaphor, deciding which mappings are activated in a given context. Second, relevance theory holds that metaphor is interpreted as deriving strong and weak implicatures within it, neglecting a fact: metaphor, as a cognitive means and a mode of thought human beings, employ frequently, differs from other figurative phenomena. Third, the communication which occurs in advertising is ostensive-inferential between advertisers and their audience. First, however, the study discussed the use of metaphor in western advertisements in general.

Morris and Waldman (2011) carried out a study to determine how and why advertisements employ metaphors and how they are different across countries and how cultural features are utilized to produce compelling advertising messages. The study analyzed 87 advertisements of food and beverage, cars, personal care, and insurance/finance from five western countries: France, Germany, Italy, Holland, and America. Their findings indicate how language and symbols represent culture. The study reported that advertisements use metaphors in visuals, texts, and headlines to capture the public's attention in the given countries globally. Nevertheless, within the particular context of each country, advertisements make use of metaphors and cultural characteristics quite differently with diverse strategies to gain interest, capture attention, and persuade the people into purchasing their products. The study's findings are interesting; however, the study compared the use of metaphor among countries with a lot of commonalities and subtle differences. The study also used a minimal number of car advertisements that may not be a good representative of car advertisements in the given contexts. So, these limitations call for a further study comparing metaphor among the countries with immense cultural differences.

Dohaei and Ketabi (2015) attempted to investigate the problem of EFL students in making sense of the metaphors in advertisements and explore the hidden metaphorical strategies in the advertisements. The study involved 30 EFL students. The study model blended some theories such as Faiclough (2010), Halliday's Systemic Functional Linguistics (1994), Van Leeuven (2006), and McQuarrie and Philips (2008) to lay the solid foundation of the study. The study findings revealed that the EFL students had problems understanding the advertisements, such as syntactic, semantic, and phonological aspects of the language used in 
advertisements, as well as nonlinguistic components like colors and the represented ideologies in advertisements. However, the study did not attempt to see the use of metaphor and cultural attributes in a comparative study.

Puspasari et al. (2012) analyzed the metaphor of slogans used in car brochures. The study focused on metaphorical phrases used in the slogans of SUV car advertisements to explore the meanings of these metaphorical phrases and discuss the target audience. This qualitative study used a descriptive approach to analyze to data. The study analyzed 19 slogans and found that they used two types of metaphor: ontological (9) and personification ontological (10). The study concludes that each metaphorical expression carries its meaning according to the target audience. The findings of the study are impressive; however, the study has limitations. It only focused on the textual analysis of the car advertisements. It did not compare the use of metaphor in different car brands in different contexts. Chetia (2015) studied rhetorical devices such as metaphor, simile, and personifications in English language advertisements in India. She found that advertisements frequently use rhetorical devices. She analyzed a wide array of advertisement taglines associated with different advertisements and concluded that the use of rhetorical devices in advertisements is inevitable.

To sum up, as discussed, the reviewed studies have investigated the use of metaphor in both textual and visual forms in different types of advertisements and have come up with impressive results. However, they have some limitations and issues that need to be covered in the prospective studies. For example, studies primarily analyzed the use of metaphor in general (Zhang \& Gao, 2009), in beauty, health care, social relationships (Agnes, 2009; Martín de la Rosa (2009); Morris \& Waldman, 2011; Chetia, 2015; Dohaei and Ketabi, 2015), and very few studies with a limited number of cars (Rosa, 2009; Morris \& Waldman, 2011) or without theoretical foundations (Chetia, 2015; Puspasari et al., 2012), with only one study on the comparison of the use of metaphor cross cultures but in the very close nations with the limited number of cars (Morris \& Waldman, 2011). Moreover, past studies like Martín de la Rosa (2009) and Morris, Waldman (2011), and Puspasari et al. (2012) were limited in the number of advertisements and called for increasing the number of car advertisements for metaphorical analysis. Hence, a study is needed to compare the use of metaphor in two different cultures like Arab and western cultures.

\subsection{Studies in Arab Context}

A Gully (1996) investigated the discourse of commercial customers in visual and verbal advertisements. He noted that advertisements are associated with the contexts of schemes and genres and relationships between language and cultural representations in the discourse community. The study stresses the decisive role of intertextuality within the framework of advertisement. The study also unveiled some rhetorical devices employed in the advertisements. The study findings are interesting; however, the study did not compare metaphor across cultures and contexts.

A study by Al Jumah (2007) aimed at comparing and contrasting the use and understanding of metaphor in English and Arabic; the study also examined the effect of culture on metaphorical thinking. The study used a triangulation of different data collection methods such as textual analysis, participants' writings, conversation meetings, and questionnaires. The study reported both active and dead metaphors in the discourse of business in both languages. Some common metaphors were game/war and up/down. The study also observed that conceptual metaphors like 'life is a journey or 'time are commodities. The cultural undertones of metaphor usage show a lack of mastery of the non-literal possibility of the English language. The study findings are rewarding; however, it was limited to textual metaphors, and also, the focus was not on the car advertisement.

El-daly (2011) investigated the nature of advertisement discourse. The study focused on consumer advertising directed towards product or service promotions. Therefore, the study deals with the fundamental, most pervasive, and influential modern advertisement discourse. The study examines how language, layout, and image interact to persuade consumers. The study drew on different linguistic theories (such as psycholinguistic, pragmatic, and sociolinguistic). The study also analyzed some advertisements and explained the interrelationships between discourse and advertisement and culture. However, the study dealt with the basics of metaphorical strategies within Arab countries without comparing the western cultural context.

Kadry (2016) conducted a study to explore how visual metaphors persuade people in advertisements and what critical elements are required in visual metaphors to produce clever and coherent advertisements. The study also investigates the different types of visual metaphors in which visual metaphor was the main image

SALTeL Vol. 4, No. 2, 2021: 25-36 
of their respective design and how it influenced the persuasion process. The study found that visual metaphors help consumers gain more positive effects and build a deeper understanding of the meaning to untie the complicated parts of the advertisement. The study also indicated that visual metaphors have many roles, such as showing persuasiveness, representing the designers' creativity and innovativeness. Lastly, visual metaphors are regarded as practical tools in creating the concepts developed visually and verbally. It is a landmark study in its kind; however, it has not compared metaphors in different cultures and contexts and issues that can deepen our understanding of the different roles of metaphors in different cultural contexts.

In sum, the result of review analysis shows that the study conducted in Arab context mainly discussed the use of text or image in advertisements (El-daly, 2011), the use of metaphor only in the text (Al Jumah, 2007), a description of metaphor in limited products (Gully 1996), and the use of visual metaphor (Kadry, 2016). Moreover, all these studies are not founded on theories of CDA, particularly Fairclaugh's (2001) threedimensional model. However, no study investigated both textual and visual metaphors in car advertisements in a cross-cultural study.

\section{Method}

This qualitative study uses a descriptive method through content analysis of car advertisements to analyze the metaphorical strategies and cultural attributes in online car advertisements in the Arab and five western countries (the Netherlands, France, Germany, Italy, and the US).

\subsection{Study Sample}

The study analyzed 30 car advertisements published online on popular websites in 2016. In a study, Morris \& Waldman (2011) analyzed 24 cars. Thus, a sample of 30 might be sufficient to provide the content for the current study. The rationale for the selection of car is that: a) car companies invest a massive amount of money in a car advertisement, but there is a report of failure, and the reason is not apparent (Adbrand.com), b) car advertisement is among the top ten culture-bound advertisements (Johnson, 2010) but study in this area is underreported or lacking as highlighted in (DeMooij, 2011; Morris \& Waldman, 2011), c) there is a vast online car advertisement in the Arab world, but it is not clear how and what types of metaphors and cultural attributes are used in their advertisements to persuade their audience into purchasing their products.

\subsection{Analysis}

The study draws upon a descriptive approach through content analysis using three models: cultural (Hofstede, 2005), metaphorical (Lankoff \& Johnson, 1980), and contrastive discourse analysis (Farclough's, 2001), which are discussed in the following sections subsequently.

\subsection{Hofstede (2005) Model}

Hofstede's (2005) model has five dimensions, namely, Masculinity/Femininity, Uncertainty Avoidance, Individualism/Collectivism, Power Distance, and Long-/Short-Term Orientation, which are elaborated on in (Table 1). In addition, it covers the national culture model of Western, Arab, and East, and West African nations.

Table 3.1 Hofstede's (2005) Cultural model dimensions and description

\section{No. Dimension}

1 Masculinity/Femininity

2 Uncertainty Avoidance

\section{Description}

Regarding Masculinity/Femininity, a society is regarded as masculine when emotional gender roles are distinct, i.e., men are presumed to be tough, strong, focused on material success. At the same time, women are supposed to be tender, modest, and concerned with life quality. This assumption can be manifested in family, market, consumer behavior, education, etcetera. (Hofstede, 2005).

Uncertainty avoidance refers to the extent to which individuals in a "culture feel threatened by ambiguous or unknown situations" (Hofstede, 2005, p.167). Of course, there is more anxiety in some cultures, and people in this kind of culture are more expressive; however, anxiety levels are low in weak uncertainty avoidance countries where emotions and aggression are not supposed to be expressed. This trait can be manifested in health, shopping, education, etcetera.

Individualism/Collectivism refers to measuring the extent to which a society is an individualist, i.e., individualism versus collectivism. This 
characteristic is reflected in personality, language, and behavior in different contexts such as school, workplace, shopping, etcetera. (Hofstede, 2005).

Power Distance refers to measuring the degree of inequality in a society associated with the power distance index. For example, the $4 \quad$ Power Distance power distance differences between countries are manifested in role pairs of teacher-student, parent-child, authority-citizen, and bosssubordinate (Hofstede, 2005).

In Long-/Short-Term Orientation, long-term orientation is associated with the idea of focusing on the future, while short-term orientation is connected with focusing on the present or past and considering them more important than the future. A country with short-term orientation values tradition and the present social hierarchy and satisfying social obligations (Hofstede, 2005).

Hofstede (2005) attributes cultural scoring to different culture dimensions in different countries differently, as demonstrated in Table 2.

Table 2: Hofstede (2005) Cultural Attribute Scoring

\begin{tabular}{lllllll} 
CULTURE DIMENSION & FRANCE & GERMANY & ITALY & HOLLAND & THE US & ARAB \\
\hline Masculinity/Femininity & 43 & 66 & 70 & 14 & 62 & 53 \\
Uncertainty Avoidance & 86 & 65 & 75 & 53 & 46 & 68 \\
Individualism/Collectivism & 71 & 67 & 76 & 80 & 91 & 80 \\
Power Distance & 68 & 35 & 50 & 38 & 40 & 57 \\
Long-/Short-Term Orientation & 39 & 29 & 34 & 44 & 31 & 28
\end{tabular}

Hofstede's (2005) model was adopted in the past study on the relationship between consumer and animosity and reluctance to purchase products (Latif et al. 2019), and car advertisement in the context of west countries (Morris \& Waldman, 2011). Therefore, this study uses this model to analyze and interpret car advertisement contents. Another model used for car advertisement content analysis is metaphor types discussed in the following section.

\subsection{The Metaphor Types}

This study attempted to identify the three types of metaphors, namely, orientational, ontological, and structural in car advertisements in a comparative study in the Arab world and in western context (The Netherlands, France, Italy, Germany, and the US), which are elaborated in Table 3

Tabel 3.3 Metaphorical (orientational, ontological, and structural) and descriptions (Lankoff \& Johnson, 1980)

\section{No. Dimension Description}

Orientation metaphors use one notion structured in terms of another in spatial orientation: "up is happy, down is sad", and are based on culture, not on random

1 Orientational choice. For example, The German ad for Lexus RX 450h uses an orientation metaphor in the headline: "Fahrensievoraus," or "Drive ahead." In addition, the tagline, "Reach Higher," is an orientation metaphor (de Mooj 2010; Morris \& Waldman 2011; Puspasari et al. 2012).

Ontological metaphors refer to concepts in terms of objects, substances, or discrete entities, as in "I'm a little rusty" or "He broke down". For example, in a study, Morris

2 Ontological and Waldman (2011) found that the Italian ad for Hyundai, headlined "L'auto con grand idea," or "The car with grand ideas," is an ontological metaphor as it considers that cars have ideas (de Mooj 2010; Morris \& Waldman 2011; Puspasari et al. 2012).

3 Structural Structural metaphors introduce similarities between concepts and objects: "Ideas are food", as both can be eaten and digested, and "argument is war" as both can be fought. 
For example, The Lincoln ad features the car on a plain white background and the headline - "Cleaner. Faster. Smarter."—demonstrates the direct injection technology that allows the car to be cleaner, faster, and more intelligent, a structural metaphor (de Mooj 2010; Morris \& Waldman 2011; Puspasari et al. 2012).

Past studies have used this metaphorical model in the car advertisement context (de Mooj 2010; Morris \& Waldman 2011; Puspasari et al. 2012). Hence, this study will adopt this model to guide the analysis and interpretation of car advertisement contents. In addition, another model, which is known as contrastive discourse analysis, is adopted by the current study, which will be deliberated below.

\subsection{Fairclough's (2001) Three Dimensional Model}

Fairclough (2001) uses contrastive discourse analysis (CDA) as an approach to investigate domination as a resource in social change and struggles against exploitation and cultural changes. In this approach, he primarily focused on institutional and power study. His approach comprises three components: the target of analysis (verbal, visual, and visual texts), the method of receiving and producing text (speaking, viewing, writing, listening, designing, reading), and all conditions (critical aspects of socio-historical conditions) which are interrelated. Eventually, Fairclough (2001) proposed three aspects to analyze any text critically: text analysis, processing analysis (, and social analysis, which are illustrated in Table 4 and Figure 1.

Table 4. Fairclough's (2001) Three Dimensional Model

\section{NO. DIMENSION}

1 Text (Description)

2 Discursive practice (interpretation)

3 Social practice (Explanation)

\section{DESCRIPTION}

The text refers to the linguistic features of the text such as text structure, grammar, lexicalization, and cohesion (Fairclough, 2001)

Discursive practice is associated with producing and consuming text such as the 'force' of utterance, intertextuality, coherence, and interdiscursivity (Fairclough, 2001).

Social practice refers to the organizational and institutional circumstances of the discursive events and the constitutive impact of discourse (Fairclough, 2001).

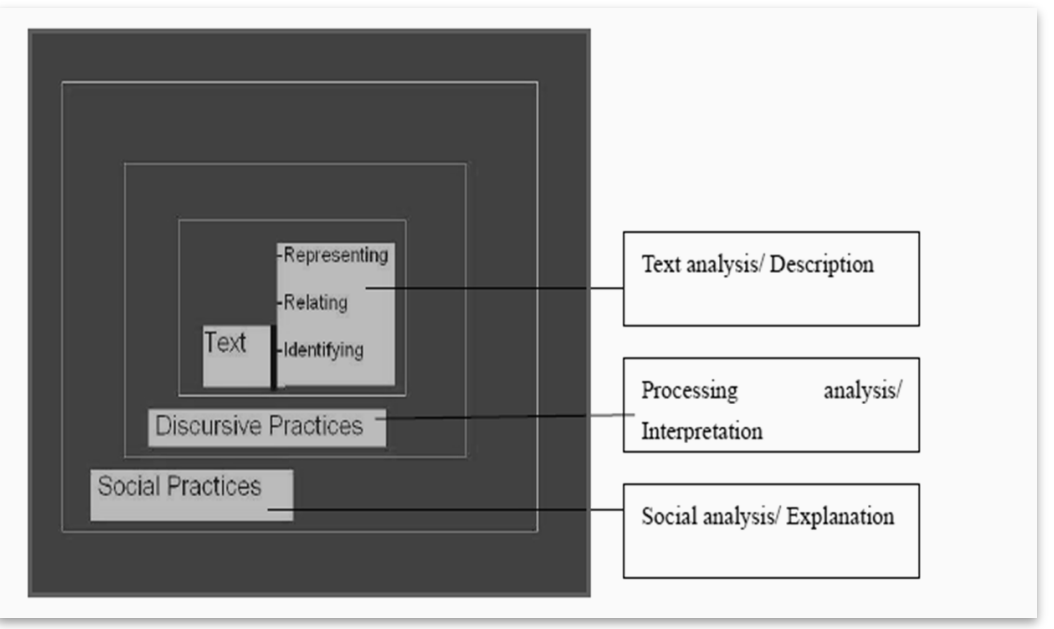

Figure 3.1 Fairclough's (2001) Three Dimensional Model

Fairclough's (2001) CDA with three dimensions has widely been reported in the literature on the use of metaphor in advertisements (Phakdeephasook 2009; Rosa 2009; Agnes 2009; Vahid 2012; Dohaei \& Ketabi 2015). It is assumed that this model can be in the context of car advertisement as well.

\section{Results and Discussion}

\subsection{The Results}

This section presents the results of content analysis of 30 car advertisements from 6 countries. It is observed that the car advertisements in each Arab and western country reflect the cultural aspects.

In the Arab context, a slogan of GMC reads: 'this is the cub of a lion'. Here, the metaphor is ontology as there is an analogy between The GMC car and a lion. This is because the lion in Arab culture is the symbol of power. A Hyundai tagline reads: 'your comfort' whose metaphor is structural. In 'your comfort', the advertisement directly tarA the audience who sees the advert by using the pronoun 'you. In a Toyota tagline 
reads: 'doomed unprecedented' (Figure 2), which is also a structural metaphor. In another Toyota tagline, it reads 'a new kind of luxury ahead of its time. Here, the metaphor is orientation. It also reflects the audience's cultural values and traits. It means that the target audience is affluent and looking for expensive, luxurious cars. Here, the advertiser has artistically portrayed the 'sea and ship' in the background to reflect the cultural value of the context of the advertisement. In a Hyundai tagline, it reads: 'makes your world comfortable'. Here there is personification ontology since this car can give you comfort and relaxation where the advertiser skillfully combines different cultural values and serotypes such as modern desert life with the most prominent world tower. The car is heading towards modernism. It means that from traditional (desert), it moves towards modem life (city), a visual orientational metaphor. In the Arab context, uncertainty avoidance is relatively high. Therefore, the Arab look for comfort, fastness, design, and excitement. They prefer form

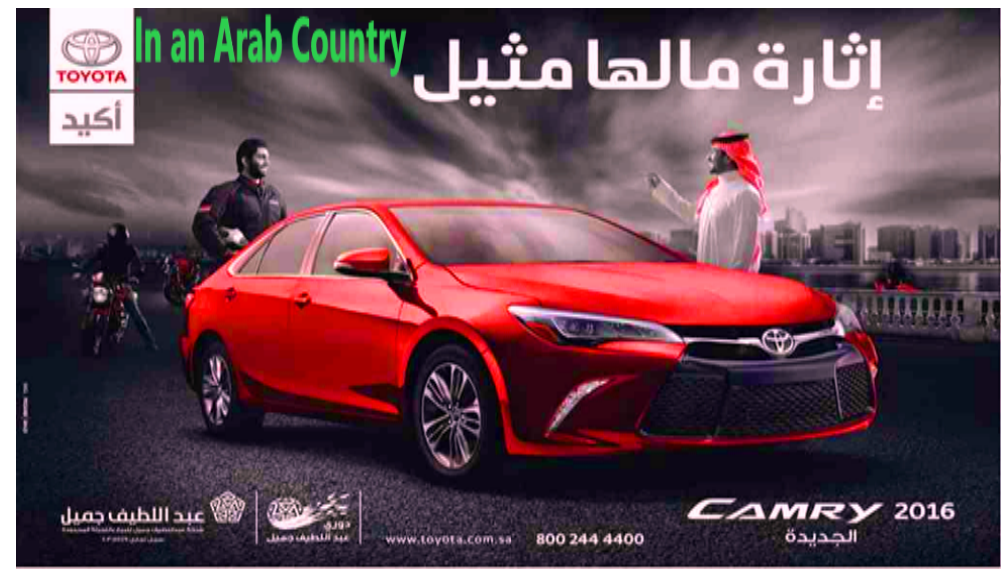

and image over function, while Westerners look for meaning and function.

Figure 4.1 Sample Car Advertisement in Arab Context

In Germany, in Buik Regal tagline: 'listen closely, and you may detect a German accent'. The advertiser uses personification and ontology by pretending that the car speaks. It is also using imperative verbs 'listen' and 'detect'. The car is driving fast, which is a visual orientational metaphor. Since the German customers seek details about the car feature, the advertiser has provided much information about the car's characteristics, options, and technology (Morris and Waldman, 2011). In the Mercedes slogan tagline, we read park wherever you want because you are driving Mercedes'. Here, the metaphor is orientational. The advertiser shows that Mercedes a big brand and trustable. This is precisely what the German look for high quality, high technology, and fast. In the Audi tagline, we read: 'Kapola, ski jump', the metaphor is ontological and orientational. The car is shown as if skiing. This picture is depicting the culture and nature in the context of the target country. Thus, German consumers look for fast acceleration, advanced technology, and design in style and function. They also seek more verification, such as expertise, and look for explanation and verification to assure the car quality.

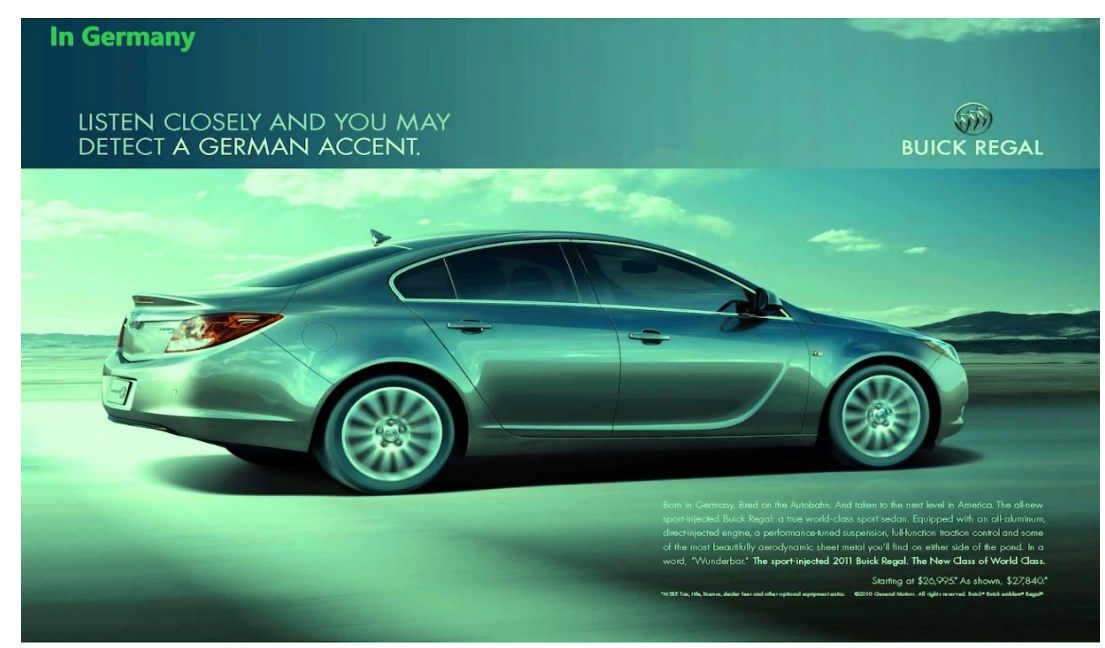

Figure 4.2 Sample of Car Advertisement in Germany 
In France's context, a slogan related to Citroen reads: 'do something great with electricity'. The advertiser wants to show the people's intention to the clean and economical car which is futuristic. The car is delicate and stylish as the French favor. The advert is also imperative since it is starting with the word 'do'. In another Citroen tagline, we read: 'Citroen C4, Technologia', while a robot is in front of the car. It shows the intention of the French for advanced, developed as well as stylish cars. Another slogan related to Fiat, 'A copy of original happiness', is the translation of "Le Bonheur en version original" (Figure 4), showing the structural metaphor. Therefore, the French like to see more design, technology, style, and fashion in car advertisements (de Mooij, 2000). Their society is not masculine, and men and women are equal, so they look for stylish, fashionable, and comfortable cars more.

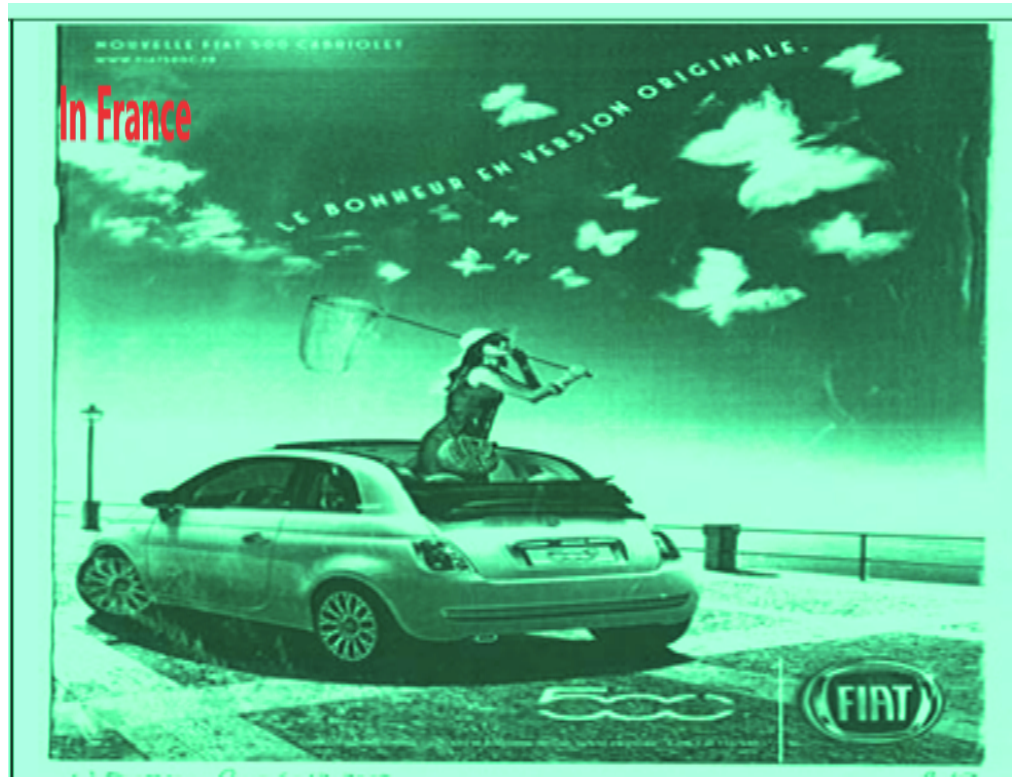

Figure 4.3 Sample of Car Advertisement in France

In the Netherlands, The Dutch, with low uncertainty avoidance and high femininity attributes, look for value and safety more than consumers in the other four nations (de Mooij, 2000). Therefore, they seek more economical 'electric' cars than 'gasoline', indicating that they are futuristic with a long-term orientation. Therefore, the word 'ELECTRIC' beside the car has a connotative meaning and suggests that the car is economical, a feature that is favorable in the context of the Dutch country (Figure 5). Furthermore, the image of a bicycle behind the car also implies that this type of car drives economically.

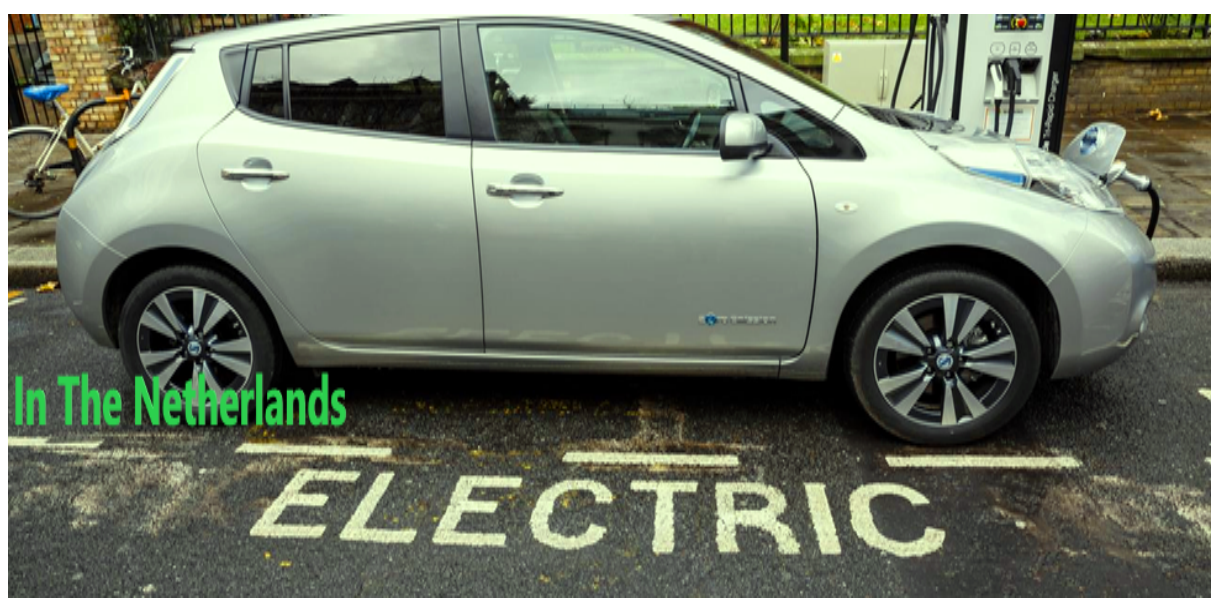

Figure 4.4 Sample of Car Advertisement in the Netherlands

The Italian context indicates that Italians look for fast acceleration, advanced technology, design, style, and function. The word 'legend edition' represents design and style. The color and shape represent design and style, expensive. They add that it has provided details about the car with the price tag since it can be afforded by a few people to purchase. 


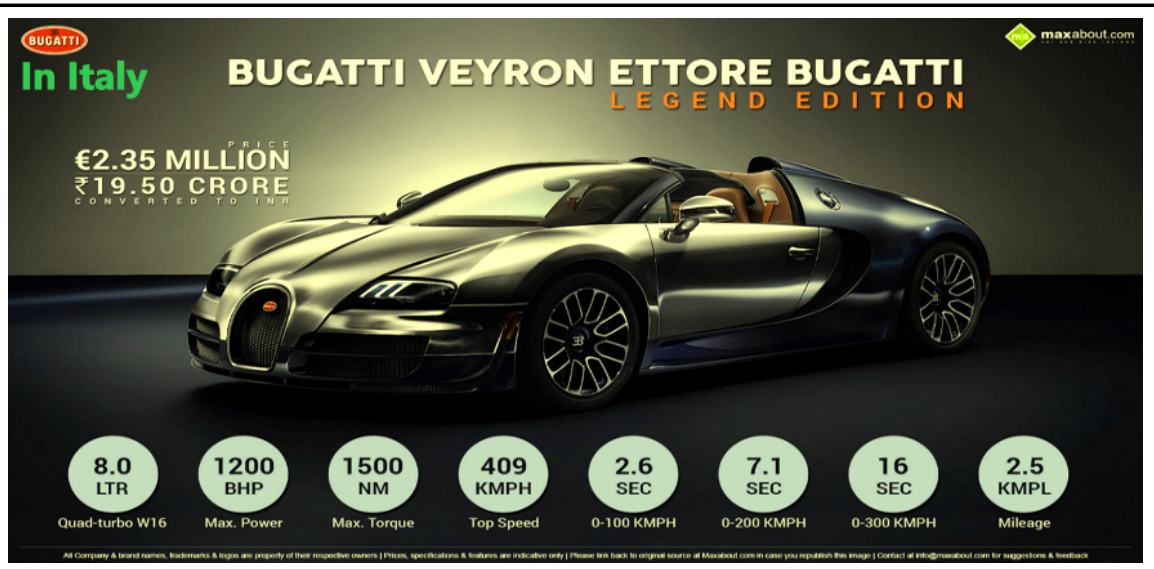

Figure 4.5 Sample of Car Advertisement in Italy

American consumers look at cars as status symbols in the US and want robust, big, powerful cars, partly because of their high masculinity score and low uncertainty avoidance attributes. For example, in the tagline, 'built tough', the metaphor is structural. As the advertisement portrays, the Americans look for strength, function, toughness, and robustness.

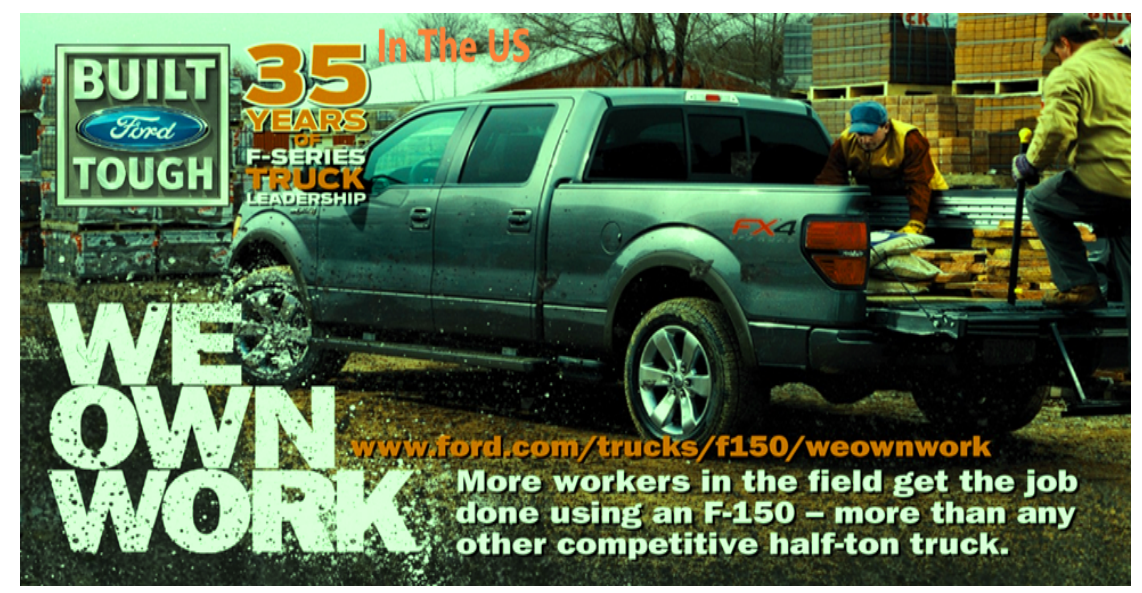

Figure 4.6 Sample of Car Advertisement in the United States

\subsection{Discussion}

The results of analysis of the use of metaphors through Fairclaough's (2001) three dimensions and Hoftse's (2005) cultural model indicate that the advertisers in different countries use metaphors and figurative language in both text and image-based on their cultural values, stereotypes, religion and traditions (Morris \& Waldman, 2011; Puspasari et al., 2012).

In the Arab context, it is observed that the use of metaphor in car advertisements in Arab countries is heavily affected by cultural values. For example, in the Arab culture, due to the impact of Islamic cultural values, nudity is avoided, and any kind of nudity is frowned upon, while in the French car advertisement, there is a woman in typical western clothes, which is not acceptable in the Arab culture. Furthermore, since, in the Arab culture, it is rude to talk directly about the price of the product or service, advertisers rarely use price tags in their advertisements. Nevertheless, as noted in the western context, the advertiser talks about the price of the car, and it is traditionally accepted.

In the Arab culture, people briefly introduce each other, and emotion and feeling are essential. As a result, in an advertisement, the form is more important than function and meaning. Besides, the effect is more significant than the accuracy. That is why it is observed that in the Arab car advertisements, the advertisers briefly introduce the car, and that satisfies the customer, while in a western context like Germany or Italy, there is much information about car features and technologies. It means that to the western people, accuracy and function are more critical than effect and image. As noted, the Arabs accept Toyota because of its popularity and reputation, and there are no details about this car in their advertisements; however, westerns ask for details as their adverts are abundant with car features.

Arab people are interested in stereotypes and their cultural values and want them to be respected and reflected in different aspects of their lives. Therefore, it is noted that in some car advertisements, the oil-well, 
Egypt pyramids, the traditional clothes, sea, ship, camel, deserts, etcetera. They are used in the backgrounds of the advertisements to intensify the impact of the advertisement on the audience and manipulate them.

Humanitarianism is another cultural attribute in the context of advertisements in Arab countries. Correspondingly, some companies like the car industry attempt to show their sympathy and support for the unprivileged people and provide financial support. Accordingly, they attract the attention of customers, particularly the well-to-do. Interestingly, the advertisers in both Arab and western contexts directly address their target audiences to persuade and manipulate them to purchase the car.

However, in a western context, the people generally seek attributes such as value, safety, economical (Dutch), design, style, and fashion, happiness (French), fastness, design, technology, style, options, details, expert verification (German), fastness, design, style, technology, expensive (Italian) and considerable, power, and spaciousness in cars (the US) (Morris \& Waldman, 2011). Overall, the westerns are more long-term oriented than their Arab counterparts since they are looking for clean, economical fuel alternatives to oil products.

Therefore, advertisers need to invest time in gaining insights into the cultural values of the target audience before designing their advertisements (Hofstede, 2005; Morris \& Waldman, 2011; Kadry, 2016). Martín de la Rosa (2009) showed that advertisements expand some cultural values such as freedom, style, volume, appearance, and modernity to manipulate people to purchase the products

\section{Conclusion}

The present study indicated that the car advertisements in each country reflect the cultural values of the respective country. The data analysis indicated that advertisers use metaphors through the Fairclaogh (2001) CDA and three dimensions. Further, Hofstede (2005) Cultural Scoring is approved though cautiously. For example, the Dutch look for high-value and economical cars, consistent with their low uncertainty avoidance and high femininity attributes.

Meanwhile, on the other hand, the Arabs look for image, emotion, brand, comfort, fastness, excitement, and design, which are primarily associated with masculinity. They also look for brands to be outstanding among others as they have high collectivism features. The western, in general, look for style, design, function, futuristic tech technology, power, and spaciousness though they have subtle differences as German seek expertise verification.

Both textual and visual analysis verified Fareclough's (2001) theory. At the textual level, different words and phrases affect, persuade, and manipulate the audience. At the discourse level, different strategies such as switch codes, metaphor (textual and visual), stereotypes, religion, cultural values, figurative speech, background color, style, and design are used to impress the reader or viewer. Finally, at a social practice level, the advertisement of each country is attempting to persuade and manipulate based on their cultural values, variations, and preference to purchase the cars.

We may get to comprehend the differences and similarities of preferences for both contexts and culture through this analysis and findings. In addition, these findings might be helpful for car advertisers in every country to choose strategies suited to their consumers because there are many interpretations behind every metaphor, code, logo, image, and tagline, thus needing to be carefully considered to ensure those advertisements are worthy of investing and spent and avoid any miscommunication.

\section{References}

Adbrand.com. http://adbrand.com/

Ágnes, A. (2009). The use of metaphors in advertising. Argumentum, 5, 18-24.

Al Jumah, F. H. (2007). A comparative study of metaphor in Arabic and English general business writing with teaching implications. Doctoral dissertation, Indiana University of Pennsylvania.

Chetia, B. (2015). Rhetorical Devices in English Advertisement Texts in India: A Descriptive Study. International Journal of Social Science and Humanity, 5(11), 980.

De Mooij, M., \& Hofstede, G. (2011). Cross-cultural consumer behavior: A review of research findings. Journal of international consumer marketing, 23(3-4), 181-192.

de Mooij, M. (2011). Consumer behavior and culture: Consequences for global marketing and advertising, 2nd ed. Thousand Oaks, CA: Sage Publications.

Dohaei, M., \&Ketabi, S. (2015). A Discourse Analysis of Coffee and Chocolate Print Advertisements: Persian EFL Learner's Problems in Focus. Mediterranean Journal of Social Sciences, 6(3 S1), 220. 
El-Daly, H. M. (2011). Towards an Understanding of the Discourse of Advertising: Review of Research with Special Reference to the Egyptian Media. African Nebula, 1(3).

Ezeifeka, C. R. (2013). Strategic Use of Metaphor in Nigerian Newspaper Reports: A Critical Perspective. Crit. Approaches Discourse Anal. Across Disciplines, 6(2), 174-192.

Fairclough, N. (1993). Critical discourse analysis and the marketization of public discourse: The universities. Discourse \& Society, 4(2), 133-168.

Fairclough, N. (2001). Language and power, 2nd Edn. New York, NY: Longman.

Fairclough, D. L. (2010). Design and analysis of quality of life studies in clinical trials. CRC press.

Gully, A. (1996). The discourse of Arabic advertising: Preliminary investigations. Journal of Arabic and Islamic studies, 1-49.

Hofstede, G. H. (2005) Cultures and Organizations: Software of the mind. ISBN 0-07-143959-5, New York: Mcgraw-hill.

Hodge, R., \& Kress, G. R. (1993). Language as ideology (Vol. 2). London: Routledge.

Johnson, B. (2010, December 06). 100 global marketers. Advertising Age, 81(43) 10-11.

Kadry, A. (2016). The Persuasive effect of using Visual Metaphors in Advertising Design. International Design Journal, 6(1), 33-40.

Kaplan, S. J. (1990). Visual metaphors in the representation of communication technology. Critical Studies in Mass Communication, 7(1), 37-47.

Kövecses, Z. (2010). Metaphor and culture. Acta Universitatis Sapientiae, Philologica, 2(2), 197- 220.

Lakoff, G., \& Johnson, M. (1980). Metaphors we live by. Chicago: University of Chicago Press.

Martín de la Rosa, V. (2009). The role of pictorial metaphor in magazine advertising.

McQuarrie, E. F., \& Philips, B. J. (2008). Go figures: New directions in advertising rhetoric. (Eds). New York: M. E. Sharpe.

Zhang, X., \& Gao, X. (2009). An analysis of conceptual metaphor in Western commercial advertisements. Asian Social Science, 5(12), 97-104.

Latif, K., Pitafi, A. H., Malik, M. Y., \& Latif, Z. (2019). Individual cultural values and consumer animosity: Chinese consumers' attitude toward American products. Sage Open, 9(3), 2158244019871056.

Morris, P. K., \& Waldman, J. A. (2011). Culture and metaphors in advertisements: France, Germany, Italy, the Netherlands, and the United States. International Journal of Communication, 5, 27.

Paltridge, B., \& Burton, J. (2000). Making sense of discourse analysis. Gold Coast.

Puspasari, A. (2012). Metaphors Found in Car Advertisements. BinaBahasa, 2(2), 61-74.

Van Leeuwen, T. (2006). Towards a semiotics of typography. Information design journal, 14(2), 139-155. 